Original Article

\title{
The influence of a medio-lateral unstable sole on invertor and evertor activation while descending stairs
}

\author{
Ki-SiK Yang, BSc, PT ${ }^{1)}$, Kyungyeon Park, PhD, RN²), Bo-RAm ChOI, PhD, $\mathrm{PT}^{3)^{*}}$ \\ 1) Department of Physical Therapy, Graduate School, Silla University, Republic of Korea \\ 2) Department of Nursing, College of Health and Welfare, Silla University, Republic of Korea \\ 3) Department of Physical Therapy, College of Health and Welfare, Silla University: \\ 315 Euisaengmyung-gwan, 700 Bakyangdae-ro, Sasang-gu, Busan 46958, Republic of Korea
}

\begin{abstract}
Purpose] This study examined the effects of a medio-lateral unstable sole on invertor and evertor activation while descending stairs. [Subjects and Methods] The subjects were 30 university students with no history of ankle sprain. They descended stairs while wearing the medio-lateral unstable sole or with bare feet. Electromyography was used to record the activity of the tibialis anterior and peroneus longus and brevis muscles and paired t-tests were used to assess statistical significance. [Results] The medio-lateral unstable sole group showed increased tibialis anterior and peroneus longus and brevis muscle activation compared to the barefoot group. [Conclusion] Medio-lateral unstable sole can be used with exercises to prevent further ankle damage by activating both the inversion and eversion muscles.

Key words: Exercise sandal, Lateral ankle sprain, Medio-lateral unstable sole (MLUS)
\end{abstract}

(This article was submitted Mar. 4, 2016, and was accepted May 7, 2016)

\section{INTRODUCTION}

Lateral ankle sprain is one of the most frequent musculoskeletal injuries. Hyper-stretching of the lateral collateral ligament of the ankle often occurs while descending stairs and landing incorrectly on the foot. This leads to pain and swelling, which interferes with activities of daily living ${ }^{1-3)}$. The tibialis anterior (TA) and peroneus longus and brevis (PL and PB) muscles play important roles in the dynamic stability of the ankle. Activation of these muscles decreases ankle sprains caused by excessive supination ${ }^{4}$. A medial wedge in the shoe induces ankle joint inversion and stimulates evertor activation more than invertor activation ${ }^{5)}$. Ankle inversion causes reflex contraction of the peroneus longus ${ }^{6}$, which controls ankle mobilization and protects against lateral ankle sprain ${ }^{7}$.

Studies have proposed methods to prevent lateral ankle sprain ${ }^{8,9)}$. Exercise sandals (Orthopedic Physical Therapy Products, Minneapolis, MN, USA) with hemispherical soles increase TA and PL muscle activation during one-leg standing ${ }^{10)}$, and decrease movement of the anteroposterior and mediolateral pressure centers in patients with functional ankle instability through functional balance training (including walking, lunging, and squatting) ${ }^{11)}$. However, because the hemispherical structures in those studies were attached to the soles of the exercise sandals, the evertors could not stimulate selective muscle activation preventing lateral ankle sprains.

In this study, the exercise sandals were modified using a rod instead of a hemispherical structure attached to the middle of the soles from the heel to the toe, to increase eversion muscle activation (the medio-lateral unstable sole; MLUS). The purpose of this study was to compare the activation of the PL, PB, and TA muscles with the MLUS or bare feet while descending stairs.

\footnotetext{
*Corresponding author. Bo-ram Choi (E-mail: boram@silla.ac.kr)

(C)2016 The Society of Physical Therapy Science. Published by IPEC Inc.

This is an open-access article distributed under the terms of the Creative Commons Attribution Non-Commercial No Derivatives (by-nc-nd) License $<$ http://creativecommons.org/licenses/by-nc-nd/4.0/>.
} 
Table 1. Activation of invertor and evertor (\%) while descending stair

\begin{tabular}{lccc}
\hline & Tibialis anterior & Peroneus longus & Peroneus brevis \\
\hline Bare foot & $7.80( \pm 3.74)$ & $20.92( \pm 10.41)$ & $11.63( \pm 6.29)$ \\
MLUS & $15.91( \pm 8.44)^{*}$ & $29.86( \pm 13.82)^{*}$ & $29.88( \pm 13.79)^{*}$ \\
\hline
\end{tabular}

MLUS: Medio-lateral unstable sole, ${ }^{*} \mathrm{p}<0.05$

\section{SUBJECTS AND METHODS}

The participants (14 males, 16 females; age 19-25 years) had no history of ankle sprain in the previous 6 months, or lower extremity surgery or fracture. Foot size was 260-270 mm (males) and 230-240 mm (females). The project received approval from the Human Research Ethics Committee of Silla University, and informed consent was obtained from each participant. A MyoTrace 400 and MyoResearch XP (Noraxon, Scottsdale, AZ, USA) were used to collect and process electromyography (EMG) data. The EMG signal was sampled at $1,000 \mathrm{~Hz}$ and a frequency bandwidth of 25-450 Hz. The signal around $60 \mathrm{~Hz}$ was removed to eliminate artificial noise, and the root mean square was calculated (window $300 \mathrm{~ms}$ ). Surface EMG electrodes were placed on the bellies of the TA, PL, and PB muscles, at a 2-cm inter-electrode distance. For the TA, the electrodes were placed over the area of greatest muscle activation while resisting inversion and dorsiflexion; for the PL, they were placed in the lateral plane over the superior one-third of the fibula; and for the PB, they were located one-fourth of the distance from the lateral malleolus to the fibular head. For normalization, a maximal voluntary isometric contraction was conducted in a standardized manual muscle position ${ }^{12)}$.

The MLUS was made by attaching a hemispherical rod $(4 \mathrm{~cm}$ long) to the middle of the sole of the shoe. It was not necessary to change the participants' shoes because the MLUS was removable. The participants stood on a step (27 cm high) and maintained their balance while looking to the front ${ }^{13)}$. The participants were instructed to step down off the stair onto the testing leg while moving forward. The participants kept looking forward and were not allowed to look down, with the knee joint in flexion. As the dominant leg moved toward the floor while descending, the non-dominant leg maintained balance ${ }^{14)}$. Movement velocity was controlled by setting a metronome to 30 beats per minute. The experiment involved 3 repetitions each with bare feet or with the MLUS. The independent variables were bare feet and using the MLUS and the dependent variables were activation of the PL, PB, and TA muscles. Paired t-tests were used to compare PA, PB, and TA activation. The statistical calculations were performed using SPSS (ver. 18.0; Norusis/SPSS, Chicago, IL, USA) and the significance level was set at 0.05 .

\section{RESULTS}

Table 1 summarizes muscle activation with the MLUS or bare feet while descending stairs. The activation of all muscles was greater with the MLUS than with bare feet.

\section{DISCUSSION}

Most studies of ankle sprain begin by noting that ankle sprains are the most common sports injury ${ }^{10,15,16)}$ and suggest that there should be measures to prevent ankle sprains. It is important to prevent than treat damage, as it is more difficult for a damaged joints to regain full function. In a study on volleyball athletes, a group that underwent balance training had a lower incidence of ankle sprain ${ }^{17)}$. The Biomechanical Ankle Platform System (BAPS) is effective at preventing further damage as it improves lower-limb muscle strength and proprioception sense ${ }^{18)}$. Recent, efforts have focused on increasing stability with different shoe insoles.

This study examined whether the attachment of the MLUS instead of a hemisphere, to the sole of exercise sandals stimulated activation of the evertors to a greater degree. Unlike standard exercise sandals, the modification was designed to stimulate more movement in the frontal plane (inversion and eversion). There is no need to buy a new pair of shoes because the MLUS is made with Velcro and is easily attached to the shoes, regardless of size. This study observed significantly more activation of the PL and PB, and the TA muscles with the MLUS. This is consistent with findings that subjects wearing exercise sandals showed improved TA, soleus, and PL muscle activation during one-leg standing ${ }^{10)}$. Our study may have a more practical application as it involved exercises that are similar to daily activities, such as descending stairs. Such exercises can help prevent eversion ankle sprain when performed repeatedly.

Ankle sprains usually occur with excessive plantar flexion and inversion. Hence, exercises to increase dorsiflexion and eversion are needed to prevent ankle sprains. Because the TA muscle causes both dorsiflexion and inversion, the MLUS was designed to decrease movement of plantar flexion and increase the movement of inversion and eversion while descending stairs. This study detected more activation of the eversion muscles, although there was also more activation of the TA muscle, as reported previously ${ }^{15}$. In this study, significant activation was observed in the 3 aforementioned muscles while descending 
stairs. However, it is not clear whether balance and muscle-strengthening exercises with the MLUS to prevent ankle sprains would enhance stability of the ankles and entire body. Therefore, future studies should examine whether balance and musclestrengthening exercises with the MLUS increase this stability. This study suggests that the MLUS can be used with exercises to prevent further damage to the ankles by stimulating activation of both the inversion and eversion muscles.

\section{REFERENCES}

1) McGowan RW, Pierce EF, Williams M, et al.: Athletic injury and self diminution. J Sports Med Phys Fitness, 1994, 34: 299-304. [Medline]

2) McKay GD, Goldie PA, Payne WR, et al.: Ankle injuries in basketball: injury rate and risk factors. Br J Sports Med, 2001, 35: 103-108. [Medline] [CrossRef] S) Smith RW, Reischl SF: Treatment of ankle sprains in young athletes. Am J Sports Med, 1986, 14: 465-471. [Medline] [CrossRef]

4) Mitchell A, Dyson R, Hale T, et al.: Biomechanics of ankle instability. Part 1: reaction time to simulated ankle sprain. Med Sci Sports Exerc, 2008, 40: 1515-1521. [Medline] [CrossRef]

5) Knight AC, Weimar WH: Difference in ratio of evertor to invertor activity between the dominant and nondominant legs during simulated lateral ankle sprain. J Sport Rehabil, 2013, 22: 272-278. [Medline]

6) Jackson ND, Gutierrez GM, Kaminski T: The effect of fatigue and habituation on the stretch reflex of the ankle musculature. J Electromyogr Kinesiol, 2009, 19: 75-84. [Medline] [CrossRef]

7) Hertel J: Functional anatomy, pathomechanics, and pathophysiology of lateral ankle instability. J Athl Train, 2002, 37: 364-375. [Medline]

8) Yoshida T, Tanino Y, Suzuki T: Effect of exercise therapy combining electrical therapy and balance training on functional instability resulting from ankle sprain-focus on stability of jump landing. J Phys Ther Sci, 2015, 27: 3069-3071. [Medline] [CrossRef]

9) Akbari A, Sarmadi A, Zafardanesh P: The effect of ankle taping and balance exercises on postural stability indices in healthy women. J Phys Ther Sci, 2014, 26: 763-769. [Medline] [CrossRef]

10) Troy Blackburn J, Hirth CJ, Guskiewicz KM: Exercise sandals increase lower extremity electromyographic activity during functional activities. J Athl Train, 2003, 38: 198-203. [Medline]

11) Michell TB, Ross SE, Blackburn JT, et al.: Functional balance training, with or without exercise sandals, for subjects with stable or unstable ankles. J Athl Train, 2006, 41: 393-398. [Medline]

12) Kendall FP, McCreary EK, Provance PG, et al.: Muscles: testing and function with posture and pain. 2005.

13) Igawa T, Katsuhira J: Biomechanical analysis of stair descent in patients with knee osteoarthritis. J Phys Ther Sci, 2014, 26: 629-631. [Medline] [CrossRef]

14) Hasegawa M, Oki S, Shimada T: Study on the effects of different stair-descending methods on knee angle, joint moment and joint force. J Phys Ther Sci, 2010, 22: 11-16. [CrossRef]

15) Knight AC, Weimar WH: Effects of inversion perturbation after step down on the latency of the peroneus longus and peroneus brevis. J Appl Biomech, 2011, 27: 283-290. [Medline]

16) Fu W, Fang Y, Liu Y, et al.: The effect of high-top and low-top shoes on ankle inversion kinematics and muscle activation in landing on a tilted surface. J Foot Ankle Res, 2014, 7: 14-24. [Medline] [CrossRef]

17) Emery CA, Rose MS, McAllister JR, et al.: A prevention strategy to reduce the incidence of injury in high school basketball: a cluster randomized controlled trial. Clin J Sport Med, 2007, 17: 17-24. [Medline] [CrossRef]

18) Osborne MD, Chou LS, Laskowski ER, et al.: The effect of ankle disk training on muscle reaction time in subjects with a history of ankle sprain. Am J Sports Med, 2001, 29: 627-632. [Medline] 